\title{
Pharmacist, general practitioner, and nurse perceptions, experiences, and knowledge of medication dosage form modification
}

This article was published in the following Dove Press journal:

Integrated Pharmacy Research and Practice

2I December 2013

Number of times this article has been viewed

Thi-My-Uyen Nguyen'

Esther TL Lau ${ }^{1,3}$

Kathryn J Steadman'

Julie AY Cichero'

Kaeleen Dingle ${ }^{2}$

Lisa M Nissen ${ }^{1,3}$

'School of Pharmacy, University of Queensland, Brisbane, QLD, Australia; ${ }^{2}$ School of Public Health, Queensland University of Technology, Brisbane, QLD, Australia; ${ }^{3}$ School of Clinical Sciences, Queensland University of Technology, Brisbane, QLD, Australia

Correspondence: Lisa M Nissen School of Clinical Sciences, Level 5, Q Block, Queensland University of Technology, Gardens Point, Brisbane, QLD, 400I, Australia

Tel +6I 731384404

Fax +6I 731381534

Email I.nissen@qut.edu.au
Background: People often modify oral solid dosage forms when they experience difficulty swallowing them. Modifying dosage forms may cause adverse effects to the patient, and the person undertaking the modification. Pharmacists are often the first point of contact for people in the general community seeking advice regarding medications. Nurses are at the forefront of administering medications to patients and are likely to be most directly affected by a patient's swallowing ability, while general practitioners (GPs) are expected to consider swallowing abilities when prescribing medications.

Objective: To compare the perspectives and experiences of GPs, pharmacists, and nurses regarding medication dosage form modification and their knowledge of medication modification.

Method: Questionnaires tailored to each profession were posted to $630 \mathrm{GPs}$, and links to an online version were distributed to 2,090 pharmacists and 505 nurses.

Results: When compared to pharmacists and GPs, nurses perceived that a greater proportion of the general community modified solid dosage forms. Pharmacists and GPs were most likely to consider allergies and medical history when deciding whether to prescribe or dispense a medicine, while nurses' priorities were allergies and swallowing problems when administering medications. While nurses were more likely to ask their patients about their ability to swallow medications, most health professionals reported that patients "rarely" or "never" volunteered information about swallowing difficulties. The majority of health professionals would advise a patient to crush or split noncoated non-sustained-release tablets, and would consult colleagues or reference sources for sustained-release or coated tablets. Health professionals appeared to rely heavily upon the suffix attached to medication names (which suggest modified release properties) to identify potential problems associated with modifying medications.

Conclusion: The different professional roles and responsibilities of GPs, pharmacists, and nurses are associated with different perspectives of, and experiences with, people modifying medications in the general community and knowledge about consequences of medication modification.

Keywords: crushing tablets, opening capsules, dosage form modification, health professional

\section{Introduction}

Some individuals modify solid dosage forms such as tablets or capsules because they dislike or experience difficulties with swallowing medications. ${ }^{1,2}$ Medication modification is performed for patients with nasogastric or gastrostomy feeding tubes as solid dosage forms are not appropriate. Medication modification can also occur when nonstandard doses are prescribed, or if liquid dosage forms are unavailable. ${ }^{1,3}$ Modified solid dosage forms may also be used to covertly administer medications to patients who lack the mental capacity to make a decision about their treatment. ${ }^{4,5}$ Solid dosage submit your manuscript | www.dovepress.com

Dovepress

http://dx.doi.org// 0.2147/IPRP.S53797
Integrated Pharmacy Research and Practice 2014:3 I-9

(c) (i) (5) 2014 Nguyen et al. This work is published by Dove Medical Press Limited, and licensed under Creative Commons Attribution - Non Commercial (unported, v3.0) License. The full terms of the License are available at http://creativecommons.org/licenses/by-nc/3.0/. Non-commercial uses of the work are permitted without any further permisson how to request permission may be found at: http://www.dovepress.com/permissions.php 
forms such as tablets may be modified through crushing, splitting, or chewing, while capsules may be opened. ${ }^{1,6}$ Crushing or modifying a dosage form in most instances is considered "off-label use" as it may not fall under a product's original license/registration. Consequently, any resulting liability falls with the prescriber and/or the person undertaking the modification. ${ }^{4,7}$

Dosage form modifications can be occupational hazards for the person modifying and administering the medication, ${ }^{8-11}$ and can increase the risk of clinically significant adverse effects for the patient. Altering solid dosage forms, eg, those with modified release properties, can affect the intended rate and extent of drug absorption. This increases the likelihood of adverse effects and toxicity, along with periods of subtherapeutic drug levels. ${ }^{12-14}$ There is concern that modifying solid dosage forms can also destroy coatings that protect the active ingredient, eg, drugs that are light sensitive or that are acid labile, causing them to be inactivated or broken down before they reach the intended site of action. ${ }^{15}$ Coatings can also be used to prevent drugs from causing side effects to the patient (eg, drugs that irritate the stomach can be enteric-coated), ${ }^{16}$ so modifying the solid dosage form may interfere with the coating's intended function.

When solid dosage forms are modified, the active ingredient may be lost as part of the modification and administration process. For example, there may be loss of drug due to spillage, or powder sticking to the crushing equipment or medicine cup. ${ }^{6,17}$ There is general concern that this could cause inconsistent and/or incomplete dosing of the medication, leading to a reduction in efficacy, particularly with drugs that have a narrow therapeutic window. ${ }^{1,6,7}$ This issue can be compounded if the crushed or opened dosage form results in an unpalatable taste or texture. ${ }^{18,19}$ Furthermore, cross contamination from residual drugs can occur if the uncleaned crushing equipment is shared among patients. ${ }^{20}$

It is generally advised that solid dosage forms should only be modified as a last resort. ${ }^{7}$ Potential alternatives include using the same drug that is commercially manufactured or extemporaneously compounded into a suitable dosage form, ${ }^{1,17}$ or by prescribing a different drug within the same therapeutic class that is formulated in an appropriate dosage form. ${ }^{21}$ Nevertheless, studies continuously report that patients and/or carers, along with health professionals, still modify solid dosage forms, even when more clinically appropriate alternatives are available. 1,6,17,21

In relation to issues associated with medication use, pharmacists are often the first point of contact for patients in the community and other health professionals. However, there is little research on pharmacists' perspectives, experiences, and knowledge of dosage form modification. Most of the available research has investigated the perspective of the patient/carer, ${ }^{2,22-25}$ or nurses administering modified dosage forms. ${ }^{3,5,6,21}$ While pharmacists are mentioned in the studies, no research has directly focused on their experiences or perceptions regarding dosage form modifications. As such, it would be useful to gauge the perceptions, experiences, and knowledge of pharmacists regarding dosage form modification, and how it might compare with other health professionals who are frequently involved with dosage form modifications.

The aim of this study was to explore and compare the perceptions, experiences, and knowledge of pharmacists, general practitioners (GPs), and nurses regarding the alteration of medication dosage forms.

\section{Methods}

A self-administered survey was mailed to 630 GPs across Queensland, Australia, in April 2010, with 421 in the Brisbane South Division of General Practice, 97 in the Capricornia Division of General Practice, and 112 in the Toowoomba GP Connections Division of General Practice. A link to an online version of the survey was emailed to 505 nurses registered with the University of Queensland, School of Nursing and Midwifery's alumni database in May 2010. The link was also distributed to 2,090 Queensland pharmacists in an e-newsletter from the Queensland branch of the Pharmaceutical Society of Australia.

The survey collected demographic information from the participants. The health professionals were asked for their perception of and experiences with people modifying their medication dosage forms in the general community. Participants were asked to estimate the prevalence of dosage form modification among the general community, questioned on how often they asked their patients about their swallowing ability, and how often their patients advised them of any swallowing difficulties or modifications made to solid dosage forms. The survey also explored whether health professionals regularly discussed the issue of dosage form modifications, including the alternatives, with other health professionals, and the solutions they would offer patients who had difficulty swallowing a noncoated non-sustainedrelease (non-SR) tablet, versus a sustained-release (SR) or coated tablet. Knowledge pertaining to altering dosage forms was investigated via the association of potential problems with the modification of eleven different medications. 
Statistical analysis was conducted with Kendall's tau-c test using SPSS 17.0 software (IBM Corporation, Armonk, NY, USA).

Ethical approval was obtained from the University of Queensland, School of Pharmacy Human Research Ethics Committee. The surveys were piloted on a group of pharmacists for appropriateness, readability, and understanding.

\section{Results \\ Demographics}

There was a relatively even distribution of males and females within the GP respondents, with 54\% aged 51 years or above (Table 1). The age of the pharmacist respondents was more evenly distributed, and the majority of them were women $(65 \% ; 113 / 173)$ who worked in community pharmacy. The nurse respondents tended to be young female registered nurses practicing in hospitals, but representation from a range of backgrounds was obtained (Table 1).

Table I Demographics of the health professionals surveyed

\begin{tabular}{|c|c|c|c|}
\hline Characteristics & $\begin{array}{l}\text { General } \\
\text { practitioners } \\
\mathrm{n}=|\mathbf{2}|\end{array}$ & $\begin{array}{l}\text { Pharmacists } \\
n=\mid 73\end{array}$ & $\begin{array}{l}\text { Nurses } \\
n=58\end{array}$ \\
\hline Sex ratio (M:F) & $\begin{array}{l}1.1: 1 \\
(63: 58)\end{array}$ & $\begin{array}{l}1: 1.19 \\
(60: 113)\end{array}$ & $\begin{array}{l}1: 4.8 \\
(10: 48)\end{array}$ \\
\hline \multicolumn{4}{|l|}{ Age (years) } \\
\hline$\leq 30$ & $4 \%$ & $33 \%$ & $66 \%$ \\
\hline $31-40$ & $15 \%$ & $16 \%$ & $5 \%$ \\
\hline $4 I-50$ & $27 \%$ & $17 \%$ & $9 \%$ \\
\hline $51-60$ & $41 \%$ & $18 \%$ & $16 \%$ \\
\hline$>60$ & $13 \%$ & $16 \%$ & $5 \%$ \\
\hline \multicolumn{4}{|l|}{ Years in profession } \\
\hline$\leq 5$ & $4 \%$ & $28 \%$ & $65 \%$ \\
\hline $6-10$ & $8 \%$ & $13 \%$ & $5 \%$ \\
\hline $\mathrm{II}-20$ & $23 \%$ & $12 \%$ & $2 \%$ \\
\hline $21-30$ & $35 \%$ & $18 \%$ & $12 \%$ \\
\hline$>30$ & $30 \%$ & $29 \%$ & $16 \%$ \\
\hline \multicolumn{4}{|l|}{ Professional location } \\
\hline Aged care & - & - & $12 \%$ \\
\hline Community & - & $65 \%$ & $24 \%$ \\
\hline Hospital & - & $19 \%$ & $59 \%$ \\
\hline Other & - & $16 \%$ & - \\
\hline Accreditation & - & $39 \%$ & - \\
\hline \multicolumn{4}{|l|}{ Position } \\
\hline Assistant nurse & - & - & $10 \%$ \\
\hline $\begin{array}{l}\text { Endorsed enrolled } \\
\text { nurse }\end{array}$ & - & - & $2 \%$ \\
\hline Registered nurse & - & - & $67 \%$ \\
\hline Nurse practitioner & - & - & $19 \%$ \\
\hline Midwife & - & - & $2 \%$ \\
\hline
\end{tabular}

Note: “-" denotes not applicable. Abbreviations: $M$, male; $F$, female.

\section{Perceptions}

Compared to pharmacists and GPs, nurses perceived that a greater proportion of the general community modified solid dosage forms. The most common estimate from nurses was that $30 \%$ of people in the community modified their medications, compared to $20 \%$ and $10 \%$ from GPs and pharmacists respectively (Figure 1). Few pharmacists (14\%; 24/173) and GPs $(13 \% ; 15 / 119)$ considered that more than half of the general population modified their medications, whereas $39 \%$ (17/44) of nurses held this view.

Pharmacists and GPs ranked allergies and medical history as the most important patient factors to be considered when prescribing and dispensing a medication, with swallowing problems and patient weight more frequently rated as least important (Figure 2A and B). In contrast, the most important patient factors for nurses when administering medications were swallowing problems and allergies, with patient age and weight being of lesser importance (Figure 2C). Statistically, prioritization by the health professionals was different for swallowing problems $(P<0.001)$ and medical history $(P=0.002)$ but not patient age, weight, and allergies. Pharmacists $(P<0.001)$ and GPs $(P<0.001)$ differed from nurses in their views on the importance of swallowing problems, and nurses $(P<0.03)$ and pharmacists $(P<0.001)$ differed from GPs in their perspectives on medical history (Figure 2).

\section{Experiences}

The health professionals differed in their likelihood of asking patients if they had problems swallowing their medications $(P=0.001)$. Nurses were more likely to ask their patients about their medication swallowing ability than pharmacists $(P<0.001)$ and GPs $(P<0.001)$. Patients were "often" or "always" asked about their swallowing capabilities by $53 \%$ of nurses, $14 \%$ of pharmacists, and $8 \%$ of GPs; while $43 \%$ of pharmacists, $32 \%$ of GPs, and $16 \%$ of nurses "rarely" or "never" asked their patients (Figure 3A).

When patients were not specifically asked about swallowing difficulties, there was no significant difference $(P=0.982)$ in the frequency at which patients volunteered this information to the different groups of health professionals. Only $19 \%$ of nurses, $16 \%$ of GPs, and $7 \%$ of pharmacists reported that patients would "often" or "always" volunteer information about their swallowing difficulties, while patients would "rarely" or "never" voluntarily advise $51 \%$ of pharmacists, $42 \%$ of GPs, and $36 \%$ of nurses about their medication swallowing difficulties (Figure 3B). GPs (44.6\%) were more likely than pharmacists $(5.2 \%)$ and nurses $(6.9 \%)$ to only 


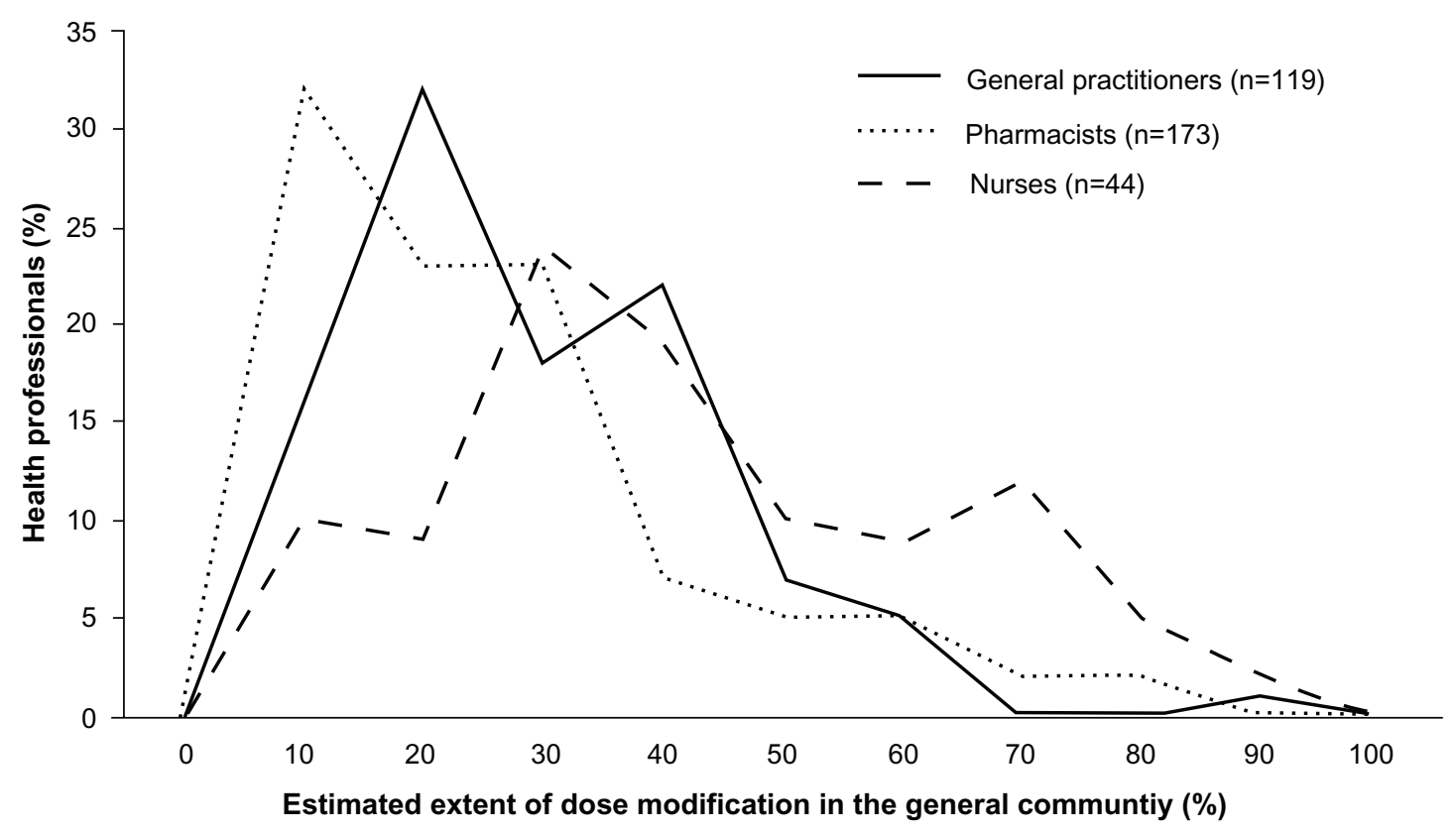

Figure I Health professionals' estimate of the percentage of people in the general community that modified their medications.

ask certain subsets of the population (such as the elderly, children, or those with known esophageal disorders) about their swallowing ability.

The majority of GPs (66\%) and pharmacists (56\%) did not regularly discuss the modification of medications, including the alternatives, with other health professionals. This was in contrast to the majority of nurses (72\%) who regularly discussed the alteration of medication dosage forms with other health professionals. The solution health professionals reportedly offered patients with difficulty swallowing non-SR and noncoated dosage forms was not significantly different ( $P=0.067)$, with the advice generally being to crush or split the tablet (Table 2). However, responses were different for SR or coated dosage forms $(P<0.001)$. The majority of nurses reported referring patients to either a pharmacist or a doctor, while GPs and pharmacists would consult reference texts, or refer patients to each other (ie, GPs would refer patients to pharmacists, while pharmacists would refer patients to GPs). A small number of health professionals reported advising patients to crush or split SR or coated dosage forms (Table 2).

\section{Knowledge}

When asked to associate problems that may arise from the modification of some common medications, $93 \%$ of GPs, $98 \%$ of pharmacists, and $84 \%$ of nurses attempted the question (Table 3). Some health professionals did not provide an answer for all of the medications, so the percentage response was calculated based on the number of respondents for each drug individually.
More than half the respondents identified that altering dosage forms with modified release properties (eg, morphine controlled-release [CR], isosorbide mononitrate SR, and verapamil SR) could lead to faster drug absorption, or an increase in adverse effects due to the change in release properties. Up to half the respondents identified concern with modifying drugs that have a narrow therapeutic index (eg, thyroxine, perhexiline, and carbamazepine), as incomplete dosing can lead to a reduction in efficacy. The majority of health professionals $(82 \%-91 \%)$ identified that modifying enteric-coated diclofenac can cause stomach irritation, but only $40 \%$ of nurses, $62 \%$ of GPs, and $73 \%$ of pharmacists identified stomach irritation as a potential problem when modified ferrous sulphate tablets are administered to a patient. More pharmacists (75\%) associated the modification of azathioprine with causing harm to the administrator, compared to nurses (37\%) and GPs (34\%). However, few respondents overall identified that modifying antibiotics may also cause harm to the administrator as they can be an irritant and cause sensitization (Table 3).

\section{Discussion}

The perceptions, experiences and knowledge of health professionals on medication modification were closely associated with their professional roles. For instance, nurses are at the forefront of administering medications to patients, and are therefore most directly affected by swallowing problems. As such, when compared to pharmacists and GPs, nurses were more likely to perceive that the general community modified their medication 


\section{A}

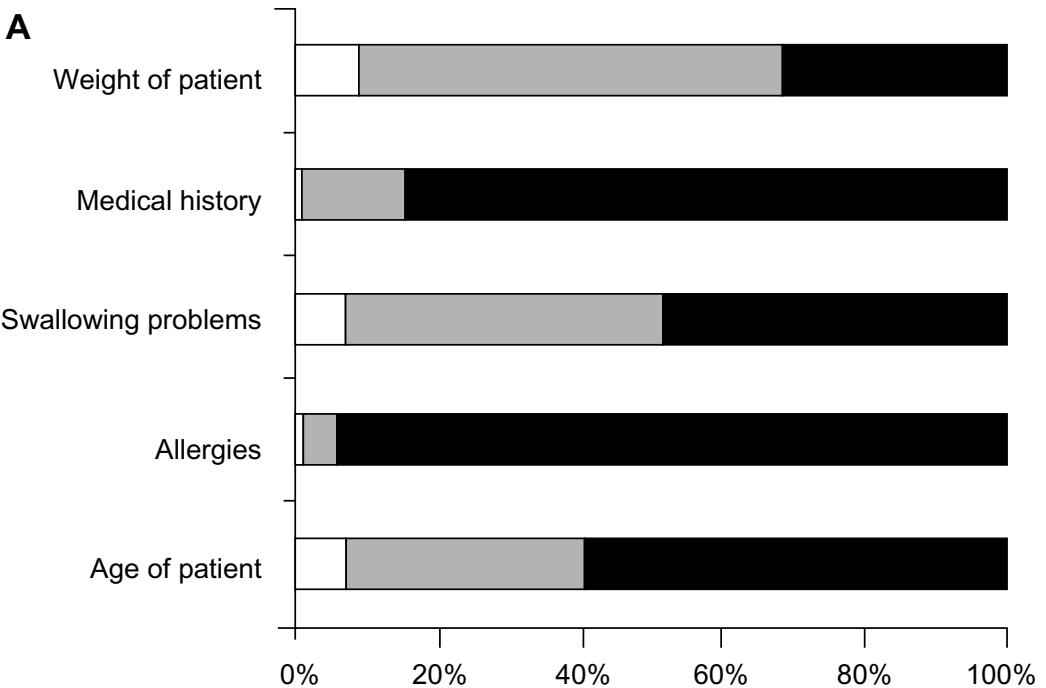

$\square$ Not important

$\square$ Important

Very important

B

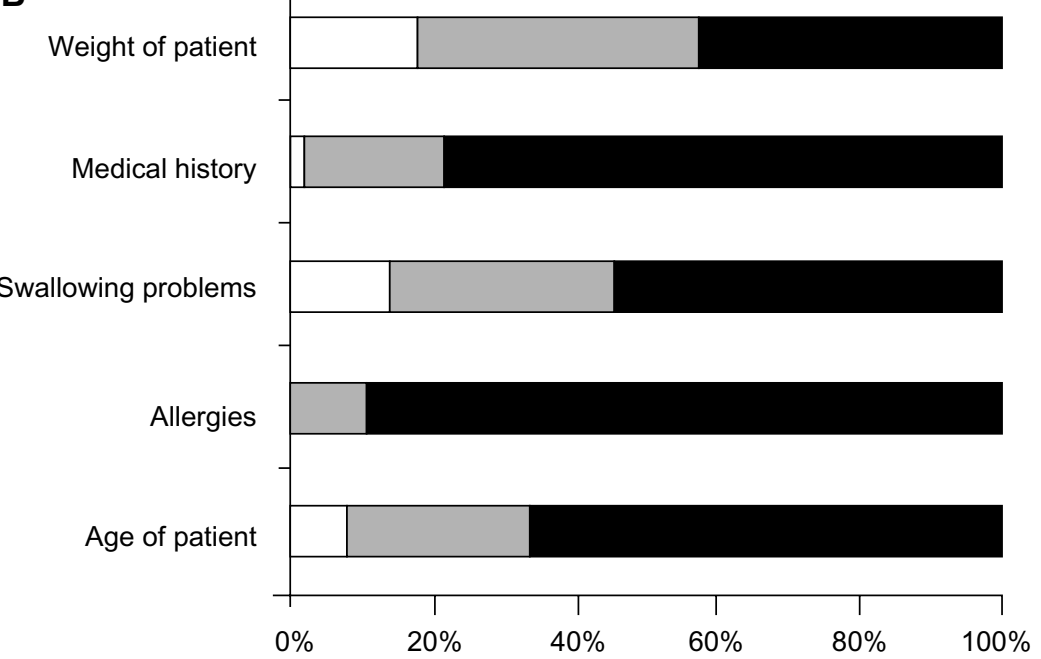

$\square$ Not important

$\square$ Important

Very important

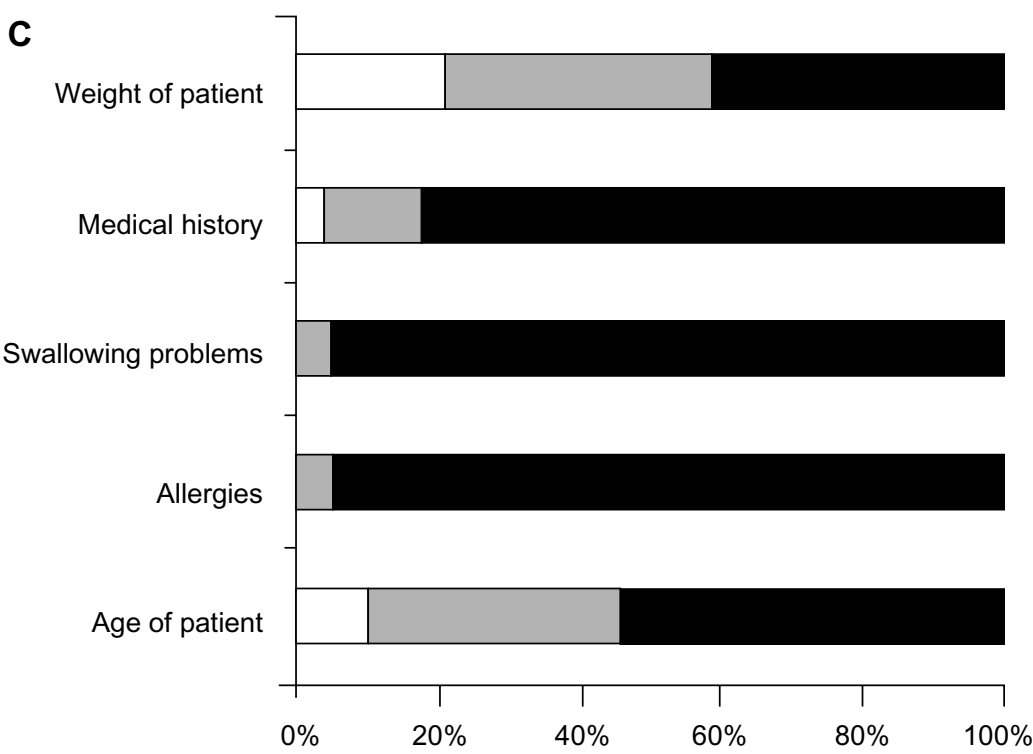

$\square$ Not important

$\square$ Important

Very important

Figure 2 The influence of patient factors on the prescribing, dispensing, and administration of medications. Notes: $(A)$ General practitioners $(n=121)$; (B) pharmacists $(n=167)$; and $(C)$ nurses $(n=44)$. 
A

General practitioners

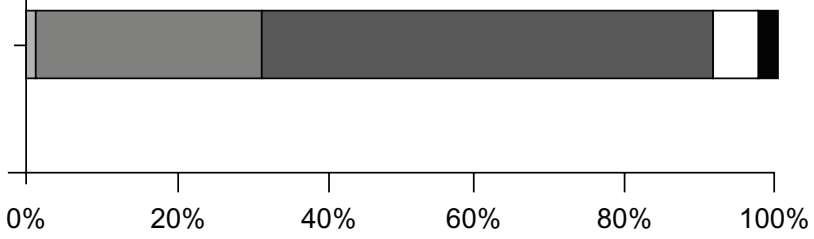

Number of health professionals asking patients (\%)

B

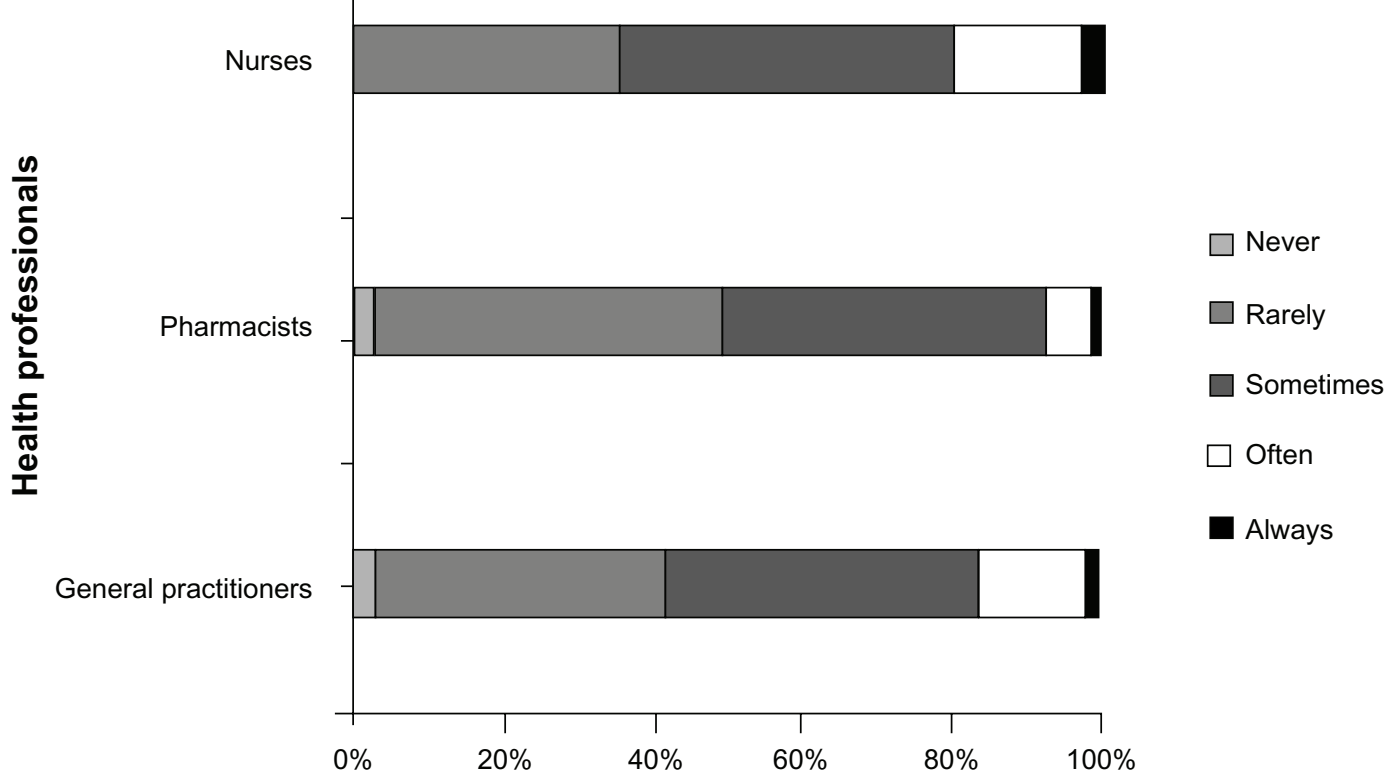

Number of health professionals being told by patients (\%)

Figure 3 Experiences of health professionals asking about patients' swallowing abilities, and being told by patients about swallowing difficulties.

Notes: The frequency of health professionals $(\mathbf{A})$ asking patients about their swallowing ability (general practitioners, $n=12$; $p h a r m a c i s t s, n=I 73 ;$ and nurses, $n=44$ ); and (B) being told about swallowing difficulties by their patients (general practitioners, $\mathrm{n}=\mathrm{I}$ I8; pharmacists, $\mathrm{n}=173$; and nurses, $\mathrm{n}=44$ ).

dosage forms. Similarly, nurses rated swallowing ability as the most important patient factor considered when administering a medication, in contrast to GPs and pharmacists.

The health professionals surveyed estimated that between $10 \%-30 \%$ of people would modify their medications. Previous studies have found patient or carer reported prevalence of medication modification in the general community to be between $24 \%{ }^{23}$ and $68 \%{ }^{24}$ This discrepancy may be because the majority of respondents reported that their patients either "rarely" or "sometimes" informed them of swallowing 
Table 2 The solution health professionals would offer patients who could not swallow a non-sustained-release and noncoated tablet, in comparison to a sustained-release or a coated tablet

\begin{tabular}{|c|c|c|c|c|c|c|}
\hline \multirow[t]{2}{*}{ Solution } & \multicolumn{2}{|c|}{ General Practitioners } & \multicolumn{2}{|l|}{ Pharmacists } & \multicolumn{2}{|l|}{ Nurses } \\
\hline & $\begin{array}{l}\text { Non-SR and } \\
\text { noncoated }(n=|| 4)\end{array}$ & $\begin{array}{l}\text { SR or coated } \\
(n=107)\end{array}$ & $\begin{array}{l}\text { Non-SR and } \\
\text { noncoated }(n=\mid 73)\end{array}$ & $\begin{array}{l}\text { SR or coated } \\
(n=173)\end{array}$ & $\begin{array}{l}\text { Non-SR and } \\
\text { noncoated }(n=58)\end{array}$ & $\begin{array}{l}\text { SR or coated } \\
(n=58)\end{array}$ \\
\hline Refer to doctor & - & - & $1 \%$ & $32 \%$ & $0 \%$ & $31 \%$ \\
\hline Refer to pharmacist & $15 \%$ & $25 \%$ & - & - & $19 \%$ & $50 \%$ \\
\hline Refer to texts & $24 \%$ & $49 \%$ & $36 \%$ & $58 \%$ & $16 \%$ & $7 \%$ \\
\hline Crush the tablet & $46 \%$ & $3 \%$ & $24 \%$ & $1 \%$ & $22 \%$ & $2 \%$ \\
\hline Split the tablet & $26 \%$ & $2 \%$ & $35 \%$ & $0 \%$ & $36 \%$ & $2 \%$ \\
\hline Other $^{\mathrm{a}}$ & $7 \%$ & $32 \%$ & $5 \%$ & $9 \%$ & $7 \%$ & $8 \%$ \\
\hline
\end{tabular}

Notes: aRefer to speech pathologist, or use alternative formulation or medication. "-” indicates results not determined.

Abbreviations: non-SR, non-sustained-release; SR, sustained-release.

difficulties voluntarily, which is consistent with reports in literature. ${ }^{19,26}$ This highlights an opportunity for health professionals to discuss and ask their patients about swallowing issues as they themselves only "sometimes" asked their patients, which might also have contributed to the health professionals' low perception of the prevalence of medication modification in the general community.

Overall, GPs were least likely to "often" or "always" ask patients about swallowing problems, but were most likely to target this questioning to patients who were predisposed, or who had pre-existing conditions that would precipitate swallowing problems. This indicates that GPs are aware swallowing problems occur more frequently in certain cohorts, but could also suggest that they may not consider people in the general community outside of these cohorts to have swallowing difficulties. Similarly, the comparatively smaller proportion of pharmacists and nurses that only ask certain subsets of the population about their swallowing ability suggests that pharmacists and nurses are generally aware that swallowing problems exist in the wider community. Alternatively, they are unaware that there are certain subsets of people in the general community who are more prone to experiencing swallowing difficulties. It is also possible these findings demonstrate that discussing swallowing problems has become an "orphan task." This is when the issue does not clearly fall within the realms of any one health professionals' defined tasks or responsibilities, so each group of health professionals assume or expect that another health professional involved in the patient's care will take responsibility and ask about swallowing problems. ${ }^{19,27}$ These findings warrant further investigations before any conclusions may be drawn as there is currently no data to suggest one interpretation is more correct than the other.

The health professionals' work environment also appeared to influence the solutions they provided to patients who had difficulty swallowing. The solutions offered to patients who had difficulty swallowing a non-SR noncoated tablet were similar among the three groups of health professionals. While crushing non-SR noncoated tablets may appear to be a reasonable approach, as stated previously, there are instances where this may not be appropriate (eg, medications that have a narrow therapeutic index). The health professionals differed in their approach when a SR or coated tablet was involved. The majority of the nurse respondents reported that they would "regularly" discuss issues pertaining to medication modifications with other health professionals, which is consistent with the majority of nurses reporting that they would refer a patient who had trouble swallowing a modified release tablet to a pharmacist or GP. This may be explained by the different workplace arrangements since most of the nurse respondents in this study worked in a hospital setting, compared to the majority of pharmacists working in community pharmacy, and GPs working in general practice. The hospital setting allows nurses to work in close proximity with other health professionals, fostering a multidisciplinary environment that facilitates discussions, in contrast to the workplace of community pharmacists and GPs, which may be less conducive to such interactions. As such, the GPs and pharmacists in this study were more likely to consult reference sources, instead of consulting with their peers.

The majority of nurse respondents in this study reported that they would consult a pharmacist or GP in relation to a SR or coated tablet. This is in contrast to published literature that report nurses performing modification to dosage forms that were unauthorized, were conducted for no apparent reason, and where modification could have been avoided as more suitable alternate forms of the medication was available. ${ }^{3,17,28}$ The discrepancy in these findings may be due to the self-reporting nature of this survey, compared to the use of focus groups and/or the observational nature of previously published studies. Nevertheless, it is of concern that a minority in all three groups of health professionals reported they would recommend patients to crush or split SR or coated tablets. It 
Table 3 Pharmacist, general practitioner, and nurse responses to a request to link potential outcomes resulting from the modification of some common medications

\begin{tabular}{|c|c|c|c|c|c|c|}
\hline Drug & $\begin{array}{l}\text { Faster drug } \\
\text { absorption }\end{array}$ & $\begin{array}{l}\text { Increase } \\
\text { adverse effects }\end{array}$ & $\begin{array}{l}\text { Hazard to } \\
\text { administrator }\end{array}$ & $\begin{array}{l}\text { Stomach } \\
\text { irritation }\end{array}$ & $\begin{array}{l}\text { Reduced } \\
\text { efficacy }\end{array}$ & $\begin{array}{l}\text { Number of } \\
\text { respondents }\end{array}$ \\
\hline \multicolumn{7}{|l|}{ Pharmacist respondents } \\
\hline Amoxycillin clavulanic acid & $21 \%$ & $35 \%$ & $3 \%$ & $60 \%$ & $24 \%$ & $|46 /| 73$ \\
\hline Azathioprine & $21 \%$ & $26 \%$ & $75 \%$ & $22 \%$ & $7 \%$ & $149 / 173$ \\
\hline Carbamazepine & $53 \%$ & $46 \%$ & $11 \%$ & $21 \%$ & $27 \%$ & $135 / 173$ \\
\hline Diclofenac EC & $22 \%$ & $49 \%$ & $2 \%$ & $91 \%$ & $12 \%$ & $167 / 173$ \\
\hline Ferrous sulphate SR & $36 \%$ & $49 \%$ & $1 \%$ & $73 \%$ & $2 \%$ & $166 / 173$ \\
\hline Isosorbide mononitrate SR & $71 \%$ & $56 \%$ & $11 \%$ & $2 \%$ & $45 \%$ & $160 / 173$ \\
\hline Metronidazole & $18 \%$ & $48 \%$ & $1 \%$ & $70 \%$ & $10 \%$ & $|4| / \mid 73$ \\
\hline Morphine CR & $83 \%$ & $62 \%$ & $12 \%$ & $5 \%$ & $30 \%$ & $167 / 173$ \\
\hline Perhexiline & $41 \%$ & $54 \%$ & $15 \%$ & $18 \%$ & $23 \%$ & $1 / 4 / 173$ \\
\hline Thyroxine & $37 \%$ & $14 \%$ & $3 \%$ & $8 \%$ & $52 \%$ & $132 / 173$ \\
\hline Verapamil SR & $76 \%$ & $58 \%$ & $9 \%$ & $6 \%$ & $36 \%$ & $160 / 173$ \\
\hline \multicolumn{7}{|c|}{ General practitioner respondents } \\
\hline Amoxycillin clavulanic acid & $23 \%$ & $42 \%$ & $0 \%$ & $54 \%$ & $27 \%$ & $97 / 121$ \\
\hline Azathioprine & $23 \%$ & $35 \%$ & $34 \%$ & $19 \%$ & $24 \%$ & $74 /|2|$ \\
\hline Carbamazepine & $53 \%$ & $52 \%$ & $5 \%$ & $8 \%$ & $34 \%$ & $79 / 121$ \\
\hline Diclofenac EC & $37 \%$ & $45 \%$ & $6 \%$ & $84 \%$ & $15 \%$ & $102 / 121$ \\
\hline Ferrous sulphate SR & $31 \%$ & $46 \%$ & $2 \%$ & $62 \%$ & $23 \%$ & $98 / 121$ \\
\hline Isosorbide mononitrate SR & $75 \%$ & $55 \%$ & $8 \%$ & $0 \%$ & $44 \%$ & $96 /|2|$ \\
\hline Metronidazole & $24 \%$ & $49 \%$ & $0 \%$ & $41 \%$ & $27 \%$ & $82 / 121$ \\
\hline Morphine CR & $75 \%$ & $57 \%$ & $9 \%$ & $6 \%$ & $36 \%$ & $108 /|2|$ \\
\hline Perhexiline & $36 \%$ & $54 \%$ & $7 \%$ & $10 \%$ & $20 \%$ & $59 / 121$ \\
\hline Thyroxine & $30 \%$ & $21 \%$ & $3 \%$ & $6 \%$ & $56 \%$ & $70 / 121$ \\
\hline Verapamil SR & $71 \%$ & $51 \%$ & $7 \%$ & $6 \%$ & $46 \%$ & $101 /|2|$ \\
\hline \multicolumn{7}{|l|}{ Nurse respondents } \\
\hline Amoxycillin clavulanic acid & $22 \%$ & $26 \%$ & $9 \%$ & $74 \%$ & $26 \%$ & $46 / 58$ \\
\hline Azathioprine & $24 \%$ & $32 \%$ & $37 \%$ & $21 \%$ & $16 \%$ & $38 / 58$ \\
\hline Carbamazepine & $37 \%$ & $37 \%$ & $16 \%$ & $21 \%$ & $50 \%$ & $38 / 58$ \\
\hline Diclofenac EC & $24 \%$ & $36 \%$ & $9 \%$ & $82 \%$ & $20 \%$ & $45 / 58$ \\
\hline Ferrous sulphate SR & $49 \%$ & $38 \%$ & $7 \%$ & $40 \%$ & $42 \%$ & $45 / 58$ \\
\hline Isosorbide mononitrate SR & $64 \%$ & $47 \%$ & $9 \%$ & $11 \%$ & $45 \%$ & $47 / 58$ \\
\hline Metronidazole & $27 \%$ & $32 \%$ & $2 \%$ & $55 \%$ & $20 \%$ & $44 / 58$ \\
\hline Morphine CR & $71 \%$ & $45 \%$ & $16 \%$ & $14 \%$ & $39 \%$ & $49 / 58$ \\
\hline Perhexiline & $20 \%$ & $40 \%$ & $20 \%$ & $23 \%$ & $23 \%$ & $35 / 58$ \\
\hline Thyroxine & $30 \%$ & $30 \%$ & $14 \%$ & $16 \%$ & $52 \%$ & $44 / 58$ \\
\hline Verapamil SR & $57 \%$ & $52 \%$ & $13 \%$ & $11 \%$ & $39 \%$ & $46 / 58$ \\
\hline
\end{tabular}

Abbreviations: $C R$, controlled-release; EC, enteric-coated; SR, sustained-release.

is inferred that health professionals had the most difficulty identifying problems associated with modifying perhexiline, thyroxine, azathioprine, carbamazepine, and metronidazole, as they more frequently omitted to provide an answer for these drugs (Table 3). This group of drugs does not have modified release properties, and therefore did not have a suffix such as "CR," "SR," or "EC," which represent "controlled-release," "sustained-release," and "enteric-coated," respectively. This suggests that health professionals are aware of the potential issues involved with altering medication dosage forms, particularly those with modified release properties, but they had to rely on the suffix of the drug names to identify those types of drugs. This is concerning as the suffix of medications are often omitted on prescriptions, ${ }^{29}$ which can lead unsuspecting health professionals to unintentionally modify medications that can lead to clinically significant adverse patient outcomes. ${ }^{12}$ This suggests that many health professionals may be less able to identify the problems associated with the alteration of medications that do not have modified release properties.

\section{Limitations}

The self-reporting nature of the survey relies on the accuracy and honesty of the respondents, so results may deviate from what actually occurs in practice. The self-selection nature of the recruitment process also provides a potential bias with "motivated responders" perhaps providing different information to targeted responders. The small sample groups may 
make it difficult to extrapolate conclusions from this study; however, it can provide an indication of views and experiences of these groups of health professionals.

\section{Conclusion}

The differing professional roles of GPs, pharmacists, and nurses are associated with different perceptions, experiences and knowledge of dosage form modification. While health professionals appear to be generally aware of problems associated with modifying dosage forms, it is likely that potential adverse events due to modification of dosage forms can be prevented via more proactive discussions with patients or carers, and through continuing professional education.

\section{Acknowledgments}

The authors would like to express appreciation to the health professionals for their participation in the study.

\section{Disclosure}

The authors declare no conflict of interest in this work. This research received no specific grant from any funding agency in the public, commercial, or not-for-profit sectors.

\section{References}

1. Nissen LM, Haywood A, Steadman KJ. Solid medication dosage form modification at the bedside and in the pharmacy of Queensland Hospitals. JPPR. 2009;39(2):129-134.

2. Hansen DL, Tulinius D, Hansen EH. Adolescents' struggles with swallowing tablets: barriers, strategies and learning. Pharm World Sci. 2008;30(1):65-69.

3. Barnes L, Cheek J, Nation RL, Gilbert A, Paradiso L, Ballantyne A. Making sure the residents get their tablets: medication administration in care homes for older people. JAdv Nurs. 2006;56(2):190-199.

4. Griffith R, Davies R. Accountability and drug administration in community care. Br J Community Nurs. 2003;8(2):65-69.

5. Treloar A, Beats B, Philpot M. A pill in the sandwich: covert medication in food and drink. $J$ R Soc Med. 2000;93(8):408-411.

6. Paradiso LM, Roughead EE, Gilbert AL, et al. Crushing or altering medications: what's happening in residential aged-care facilities? Australas J Ageing. 2002;21(3):123-127.

7. Burridge N, Deidun D, editors. Australian don't rush to crush handbook. Therapeutic Options for People Unable to Swallow Solid Oral Medicines. 1st ed. Victoria: The Society of Hospital Pharmacists of Australia; 2011.

8. Valanis B, Vollmer WM, Steele P. Occupational exposure to antineoplastic agents: self-reported miscarriages and stillbirths among nurses and pharmacists. J Occup Environ Med. 1999;41(8):632-638.

9. Valanis B, Vollmer W, Labuhn K, Glass A. Occupational exposure to antineoplastic agents and self-reported infertility among nurses and pharmacists. J Occup Environ Med. 1997;39(6):574-580.

Integrated Pharmacy Research and Practice

\section{Publish your work in this journal}

Integrated Pharmacy Research and Practice is an international, peer-reviewed, open access, online journal, publishing original research, reports, reviews and commentaries on all areas of academic and professional pharmacy practice. This journal aims to represent the academic output of pharmacists and pharmacy practice with particular focus on integrated care. All papers are carefully peer reviewed
10. Pethran A, Schierl R, Hauff K, Grimm CH, Boos KS, Nowak D. Uptake of antineoplastic agents in pharmacy and hospital personnel. Part I: monitoring of urinary concentrations. Int Arch Occup Enivron Health. 2003;76(1):5-10.

11. Ensslin AS, Huber R, Pethran A, et al. Biological monitoring of hospital pharmacy personnel occupationally exposed to cytostatic drugs: urinary excretion and cytogenetics studies. Int Arch Occup Environ Health. 1997;70(3):205-208.

12. Schier JG, Howland MA, Hoffman RS, Nelson LS. Fatality from administration of labetalol and crushed extended-release nifedipine. Ann Pharmacother. 2003;37(10):1420-1423.

13. Cornish P. "Avoid the crush": hazards of medication administration in patients with dysphagia or a feeding tube. CMAJ. 2005;172(7): 871-872.

14. Best BM, Capparelli EV, Diep H, et al. Pharmacokinetics of lopinavir/ ritonavir crushed versus whole tablets in children. J Acquir Immune Defic Syndr. 2011;58(4):385-391.

15. Horn JR, Howden CW. Similarities and differences among delayedrelease proton-pump inhibitor formulations. Aliment Pharmacol Ther. 2005;22(Suppl 3):20-24.

16. Cole AT, Hudson N, Liew LCW, Murray FE, Hawkey CJ, Heptinstall S. Protection of human gastric mucosa against aspirin - enteric coating or dose reduction? Aliment Pharmacol Ther. 1999;13(2):187-193.

17. Stubbs J, Haw C, Dickens G. Dose form modification - a common but potentially hazardous practice. A literature review and study of medication administration to older psychiatric inpatients. Int Psychogeriatr. 2008;20(3):616-627.

18. Lucas-Bouwman ME, Roorda RJ, Jansman FG, Brand PL. Crushed prednisolone tablets or oral solution for acute asthma? Arch Dis Child. 2001;84(4):347-348.

19. Kelly J, D'Cruz G, Wright D. A qualitative study of the problems surrounding medicine administration to patients with dysphagia. Dysphagia. 2009;24(1):49-56.

20. Cohen MR. Medication errors. Nursing. 1982;12(12):25.

21. Kirkevold O, Engedal K. What is the matter with crushing pills and opening capsules? Int J Nurs Pract. 2010;16(1):81-85.

22. Morris H. Dysphagia in a general practice population. Nurs Older People. 2005;17(8):20-23.

23. Quinzler R, Gasse C, Schneider A, Jaufmann-Kolle P, Saecsenyi J, Haefeli WE. The frequency of inappropriate tablet splitting in primary care. Eur J Clin Pharmacol. 2006;62(12):1065-1073.

24. Strachan I, Greener M. Medication-related swallowing difficulties may be more common than we realise. Pharm Pract. 2005;15(10):411-414.

25. Miller N, Allcock L, Hildreth AJ, Jones D, Noble E, Burn DJ. Swallowing problems in Parkinson disease: frequency and clinical correlates. J Neurol Neurosurg Psychiatry. 2009;80(9):1047-1049.

26. Bloem BR, Lagaay AM, van Beek W, Haan J, Roos RA, Wintzen AR. Prevalence of subjective dysphagia in community residents aged over 87. BMJ. 1990;300(6726):721-722.

27. Jordan S. Managing adverse drug reactions: an orphan task. JAdv Nurs. 2002;38(5):437-448.

28. Haw C, Stubbs J, Dickens G. An observational study of medication administration errors in old-age psychiatric inpatients. Int J Qual Health Care. 2007;19(4):210-216.

29. Lesar T. Prescribing errors involving medication dosage forms. J Gen Intern Med. 2002;17(8):579-587.

to ensure the highest standards as well as ensuring that we are informing and stimulating pharmaceutical professionals. The manuscript management system is completely online and includes a very quick and fair peer-review system, which is all easy to use. Visit http://www.dovepress.com/testimonials.php to read real quotes from published authors. 